\title{
Correlation of E-cadherin and CD44v6 expression with clinical pathology in esophageal carcinoma
}

\author{
WEI-DONG SHEN*, YONG JI* ${ }^{*}$ PENG-FEI LIU, BIN XIANG, GUO-QIANG CHEN, BIN HUANG and SONG WU \\ Department of Gastroenterology, The Affiliated Jangyin People's Hospital of Southeast \\ University Medical College, Jiangyin, Jiangsu 214400, P.R. China
}

Received September 7, 2011; Accepted November 30, 2011

DOI: $10.3892 / \mathrm{mmr} .2011 .693$

\begin{abstract}
Cell adhesion, important for maintaining tissue architecture, plays a role in numerous cancers and particularly in tumor progression. In the present study, we investigated perturbations in the expression of two important adhesion proteins, epithelial (E)-cadherin and CD44v6, in esophageal carcinoma (EC). EC specimens were obtained from 42 patients undergoing resection of EC; both cancer and adjacent normal tissue were collected. Expression of E-cadherin and CD44v6 was detected by immunohistochemistry and the correlation between the expression of these two proteins and their individual relationships with pathology were determined. E-cadherin expression in EC tissue was significantly less common than in adjacent normal tissue. Furthermore, absence of E-cadherin expression was correlated with infiltration depth, lymph node metastasis, distant metastases and TNM stage $(\mathrm{P}<0.05)$, but not with gender, age, differentiation or tumor size. By contrast, CD44v6 expression in EC was significantly higher than that in adjacent normal tissue and was correlated with differentiation, distant metastases and TNM stage $(\mathrm{P}<0.05)$, but not with other clinicopathological parameters. Additionally, we observed a negative correlation between E-cadherin and CD44v6 expression in EC $(\mathrm{P}<0.05)$. Based on their correlations with pathology, we suggest that the expression of E-cadherin and CD44v6 is important roles in promoting the infiltration and metastasis of EC.
\end{abstract}

\footnotetext{
Correspondence to: Dr Wei-Dong Shen, Department of Gastroenterology, The Affiliated Jangyin People's Hospital of Southeast University Medical College, Shoushan Road 163, Jiangyin, Jiangsu 214400, P.R. China

E-mail: jiyongmyp@126.com
}

${ }^{*}$ Contributed equally

Key words: esophageal carcinoma, E-cadherin, CD44v6, immunohistochemistry, cell adhesion

\section{Introduction}

Esophageal carcinoma (EC), affecting the gastrointestinal tract, is the fourth most lethal malignancy, with an average annual mortality rate of $14.59 / 100,000$ (1). As with many cancers, invasion and metastasis of these malignant tumors are the leading causes of mortality, posing one of the biggest challenges in the treatment and survival of this cancer.

One factor known to promote both invasion and metastasis is the loss of cell adhesion. Cell adhesion maintains the architecture of tissues by linking cells together or to an extracellular matrix. The aberrant expression or function of cell adhesion molecules results in loss of this architecture, providing an opportunity for tumor cells to invade and spread (2). For example, the CD44 cell adhesion molecules, which anchor cells to matrices, are closely correlated with invasion and metastasis of a number of tumors and are abnormally expressed on their cell surfaces (3). One splice variant, CD44v6, is highly correlated with the metastasis of various malignant tumors and serves as a key indicator for prognosis of patients with tumors (4). Another class of cell adhesion molecules, cadherins, which typically mediate adhesion between cells of the same type (5), have also been associated with cancer. Epithelial cadherin (E-cadherin) was identified as an important marker in evaluating tumor invasion and metastasis, and has been widely studied in various malignant tumors (6-8). Although E-cadherin is a tumor suppressor, loss of function of this cell adhesion molecule promotes tumor progression (9).

Recent studies have demonstrated associations between the loss of cell adhesion and the invasion or metastasis of EC (10). We investigated the expression of the cell adhesion molecules E-cadherin and CD44v6 in both EC and normal adjacent tissues. In particular, the correlation between the expression of these two molecules, their relationship with clinicopathological parameters and their role in the development and progression of EC were assessed.

\section{Materials and methods}

Patients. EC specimens were obtained from 42 patients undergoing resection of EC in the Affiliated Jangyin People's Hospital of Southeast University Medical College; adjacent normal tissue was also acquired. Patients included 24 males

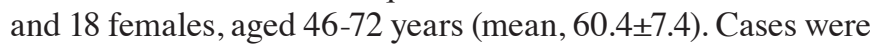



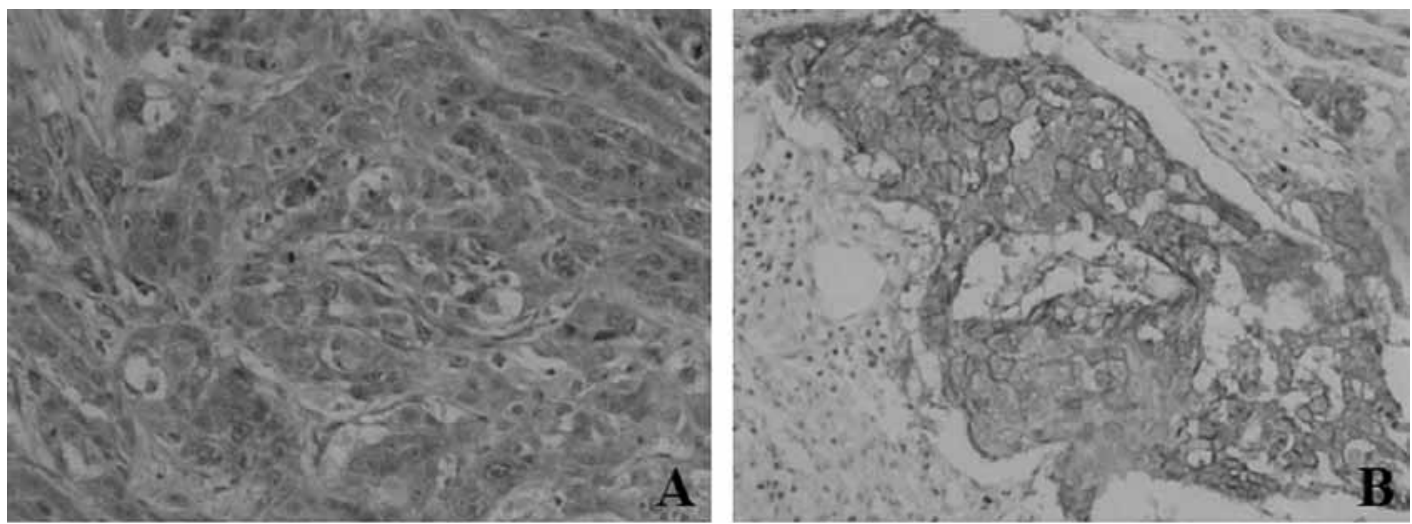

Figure 1. Positive expression of (A) E-cadherin and (B) CD44v6 in esophageal cancer (magnification, $\mathrm{x} 100$ ).

categorized according to the WHO pathological classification criteria (12), as: highly, moderately or poorly differentiated; infiltrated to the submucosa, to muscle or to the outer layer; tumor size $<5$ or $\geq 5 \mathrm{~cm}$; lymph node metastasis or no metastasis; distant metastasis or no distant metastasis; and clinical stage I and II or III and IV.

Experimental methods: Immunohistochemistry. Streptavidinbiotin-horseradish peroxidase complex (SP method; Santa Cruz Biotechnology, Santa Cruz, CA, USA) was used for immunohistochemistry of E-cadherin and CD44v6. Briefly, tissues were formalin-fixed, dehydrated, embedded for sectioning at $4 \mu \mathrm{m}$, and sections were placed onto glass slides by conventional methods. Sections were dewaxed with dimethylbenzene, dehydrated by alcohol gradient and soaked prior to antigen retrieval by high temperature. Subsequently, $3 \%$ hydrogen peroxide solution was used to block endogenous peroxidase activity; sections were covered with non-specific serum, placed in a humidified chamber and incubated at room temperature. Primary antibodies (E-cadherin or CD44v6; Santa Cruz Biotechnology) were added and slides were incubated at $4^{\circ} \mathrm{C}$ overnight. Slides were washed with (PBS) three times and biotinylated secondary antibodies were then added for incubation at room temperature. Slides were washed with PBS three times, treated with with streptococcus avidinperoxidase and incubated at $37^{\circ} \mathrm{C}$ for $30 \mathrm{~min}$. Following DAB reaction, staining was visualized by light microscopy. Sections were counterstained with hematoxylin and sealed with neutral gum. Positive tissue sections were used as a positive control, and PBS was used in place of primary antibodies as a negative control.

Ten high-power fields (x400) were selected for each case; 100 esophageal squamous cells were counted per field. Positive E-cadherin staining appears as brown granules, mainly located in the cytoplasm but also expressed in nuclei. Positive CD44v6 staining appears as brownish-yellow granules in the cell membrane. Staining results were classified according to intensity and proportion of positive cancer cells. For staining intensity, scoring was as follows: 0 indicated colorless, 1 indicated light brown, 2 indicated moderate brown and 3 indicated dark brown. For the number of positive cells, scoring was as follows: a ratio of positive to total cancer cells $<25 \%$ was scored as $0 ; 25-50 \%$ was scored as $1,50-75 \%$ was scored as 2 and $>75 \%$ scored as 3 . Scores were added together for the final determination: $<2$ was considered negative (-), 2-3 was considered weak positive (+), 3-4 was considered positive (++) and $\geq 4$ was considered strong positive (+++).

Statistical analysis. SPSS 13.0 statistical software was used for statistical analysis. The $\chi^{2}$ test was used to compare E-cadherin and CD44v6 expression, and Spearman's rank correlation was used to analyze the correlation between E-cadherin and CD44v6 expression. Analysis was performed with two-sided tests, with $\alpha$ level 0.05 . $\mathrm{P}<0.05$ was considered to indicate statistical significance.

\section{Results}

Altered E-cadherin and CD44v6 expression in EC. Histopathology of EC tissue demonstrated brown granules within the cytoplasm and nuclei, indicative of E-cadherin expression, and brownish-yellow granules in the cell membrane, indicative of CD44v6 expression (Fig. 1).

Quantitative analysis of protein expression revealed differences in the expression of cell adhesion proteins between adjacent normal tissue and EC tissue. E-cadherin was detected in only 20 samples (47.6\%) of EC tissue, but in 35 samples (83.3\%; Table I) of normal adjacent tissue. Thus, E-cadherin expression was significantly less common in $\mathrm{EC}\left(\chi^{2}=12.428\right.$, $\mathrm{p}=0.006)$. In addition, loss of E-cadherin expression in EC tissue was correlated with several pathological parameters, including depth of invasion, lymph node metastasis, distant metastasis and clinical stage $(\mathrm{p}<0.05)$, but not with gender, age, differentiation degree or tumor size (Table II).

By contrast, CD44v6 was significantly more commonly detected in EC tissue than in adjacent normal tissue. CD44v6 expression was detected in 36 samples (85.7\%) of EC, compared to only 6 samples $(14.3 \%)$ of normal adjacent tissue $\left(\chi^{2}=44.967, \mathrm{p}=0.001\right.$; Table III). Moreover, CD44v6 expression in EC was correlated with differentiation degree, distant metastasis and clinical stage $(\mathrm{p}<0.05)$, but not with gender, age, depth of invasion, tumor size or lymph node metastasis (Table IV).

Correlation between expression of E-cadherin and CD44v6 in EC. Expression of E-cadherin and CD44v6 was not only altered in EC tissue, but a negative correlation was also found between them $(r=-0.607, p=0.001)$, such that $E$-cadherin 
Table I. Expression of E-cadherin in cancer and adjacent normal tissues [n (\%)].

\begin{tabular}{|c|c|c|c|c|c|}
\hline Groups & No. & - & + & ++ & +++ \\
\hline Cancer tissues & 42 & $22(52.4)$ & $11(26.2)$ & $6(14.3)$ & $3(7.1)$ \\
\hline Adjacent normal tissues & 42 & $7(16.7)$ & $16(38.1)$ & $11(26.2)$ & $8(19.0)$ \\
\hline Total & 84 & $29(34.5)$ & $27(32.1)$ & $17(20.2)$ & $11(13.1)$ \\
\hline
\end{tabular}

$\chi^{2}=12.428, \mathrm{p}=0.006$.

Table II. Correlation between the expression of E-cadherin and clinicopathological parameters in esophageal cancer [n (\%)].

\begin{tabular}{|c|c|c|c|c|c|c|c|}
\hline Clinicopathological parameters & No. & - & + & ++ & +++ & $\chi^{2}$ & p-value \\
\hline \multicolumn{8}{|l|}{ Gender } \\
\hline Male & 24 & $11(45.8)$ & $7(29.2)$ & $4(16.7)$ & $2(8.3)$ & \multirow[t]{2}{*}{0.981} & \multirow[t]{2}{*}{0.806} \\
\hline Female & 18 & $11(61.1)$ & $4(22.2)$ & $2(11.1)$ & $1 \quad(5.6)$ & & \\
\hline \multicolumn{8}{|l|}{ Age (years) } \\
\hline$<60$ & 17 & $8(47.1)$ & $5(29.4)$ & $2(11.8)$ & $2(11.8)$ & \multirow[t]{2}{*}{1.249} & \multirow[t]{2}{*}{0.741} \\
\hline$\geq 60$ & 25 & $14(56.0)$ & $6(24.0)$ & $4(16.0)$ & $1 \quad(4.0)$ & & \\
\hline \multicolumn{8}{|l|}{ Differentiation } \\
\hline High & 9 & $4(44.4)$ & $4(33.3)$ & $2(22.2)$ & 0 & \multirow[t]{3}{*}{3.686} & \multirow[t]{3}{*}{0.719} \\
\hline Moderate & 23 & $14(60.9)$ & $4(17.4)$ & $3(13.0)$ & $2(8.7)$ & & \\
\hline Poor & 10 & $4(40.0)$ & $4(40.0)$ & $1(10.0)$ & $1(10.0)$ & & \\
\hline \multicolumn{8}{|l|}{ Infiltration depth } \\
\hline To the submucosa & 5 & $4(80.0)$ & $1(20.0)$ & 0 & 0 & \multirow[t]{3}{*}{14.740} & \multirow[t]{3}{*}{0.022} \\
\hline To the muscle & 22 & $16(72.7)$ & $3(13.6)$ & $2(9.1)$ & $1 \quad(4.5)$ & & \\
\hline To the outer layer & 15 & $2(13.3)$ & $7(46.7)$ & $4(26.7)$ & $2(13.3)$ & & \\
\hline \multicolumn{8}{|l|}{ Tumor size $(\mathrm{cm})$} \\
\hline$<5$ & 29 & $15(51.7)$ & $9(31.0)$ & $4(13.8)$ & $1 \quad(3.4)$ & \multirow[t]{2}{*}{2.653} & \multirow[t]{2}{*}{0.448} \\
\hline$\geq 5$ & 13 & $7(53.8)$ & $2(15.4)$ & $2(15.4)$ & $2(15.4)$ & & \\
\hline \multicolumn{8}{|l|}{ Lymph node metastasis } \\
\hline Yes & 18 & $4(22.2)$ & $6(33.3)$ & $5(27.8)$ & $3(16.7)$ & \multirow[t]{2}{*}{14.097} & \multirow[t]{2}{*}{0.003} \\
\hline No & 24 & $18(75.0)$ & $5(20.8)$ & $1 \quad(4.2)$ & 0 & & \\
\hline \multicolumn{8}{|l|}{ Distant metastasis } \\
\hline Yes & 23 & $6(26.1)$ & $8(34.8)$ & $6(26.1)$ & $3(13.0)$ & \multirow[t]{2}{*}{15.579} & \multirow[t]{2}{*}{0.001} \\
\hline No & 19 & $16(84.2)$ & $3(15.8)$ & 0 & 0 & & \\
\hline \multicolumn{8}{|l|}{ Clinical stage } \\
\hline $\mathrm{I}+\mathrm{II}$ & 26 & $19(73.1)$ & $6(23.1)$ & $1(3.8)$ & 0 & \multirow[t]{2}{*}{15.915} & \multirow[t]{2}{*}{0.001} \\
\hline III+IV & 16 & $3(18.8)$ & $5(31.3)$ & $5(31.3)$ & $3(18.8)$ & & \\
\hline
\end{tabular}

expression weakened with an enhanced expression of CD44v6 (Table V).

\section{Discussion}

$\mathrm{EC}$ is one of the most common tumors in clinical practice and its development is extremely complex, involving multiple stages and genes. Invasion and metastasis are the main biological characteristics of EC, as well as the main causes of treatment failure and mortality. Invasion and metastasis are also highly intricate processes with multiple steps, factors and effects. Thus, investigation into the mechanisms and prevention of invasion and metastasis constitutes an important aspect of cancer research.
Loss of cell adhesion is one factor known to promote invasion and metastasis. Several different cell adhesion molecules exist, a number of which are involved in cancer development and progression. One type of cell adhesion molecule, E-cadherin, is a transmembrane protein primarily found in epithelial cells that functions in cell-cell contact and maintains epithelial cell morphology and structural integrity (13). Loss of E-cadherin expression results in decreased adhesion between cells, leading to cell dispersal and invasive growth towards the periphery; once conditions are ideal, cells break away from the primary tumor and metastasize. This phenomenon has been observed in nasopharyngeal, ovarian, bladder cancer and pancreatic ductal adenocarcinoma (14-17). Herein, we extend the importance of E-cadherin to EC, since E-cadherin was 
Table III. Expression of CD44v6 in cancer and adjacent normal tissues [n (\%)].

\begin{tabular}{|c|c|c|c|c|c|}
\hline Groups & No. & - & + & ++ & +++ \\
\hline Cancer tissues & 42 & $6(14.3)$ & $20(47.6)$ & $9(21.4)$ & 7 (16.7) \\
\hline Adjacent normal tissues & 42 & $36(85.7)$ & $6(14.3)$ & 0 & 0 \\
\hline Total & 84 & $42(50.0)$ & $26(31.0)$ & $9(10.7)$ & $7(8.3)$ \\
\hline
\end{tabular}

$\chi^{2}=44.967, \mathrm{p}=0.001$.

Table IV. Correlation between the expression of CD44v6 and clinicopathological parameters in esophageal cancer [n (\%)].

\begin{tabular}{|c|c|c|c|c|c|c|c|}
\hline Clinicopathological parameters & No. & - & + & ++ & +++ & $\chi^{2}$ & $\mathrm{p}$-value \\
\hline \multicolumn{8}{|l|}{ Gender } \\
\hline Male & 24 & $3(12.5)$ & $14(58.3)$ & $2(8.3)$ & $5(20.8)$ & \multirow[t]{2}{*}{6.540} & \multirow[t]{2}{*}{0.088} \\
\hline Female & 18 & $3(16.7)$ & $6(33.3)$ & $7(38.9)$ & $2(11.1)$ & & \\
\hline \multicolumn{8}{|l|}{ Age (years) } \\
\hline$<60$ & 17 & $4(23.5)$ & $7(41.2)$ & $3(17.6)$ & $3(17.6)$ & \multirow[t]{2}{*}{2.614} & \multirow[t]{2}{*}{0.539} \\
\hline$\geq 60$ & 25 & $2(8.0)$ & $13(52.0)$ & $6(24.0)$ & $4(16.0)$ & & \\
\hline \multicolumn{8}{|l|}{ Differentiation } \\
\hline High & 9 & 0 & $6(66.7)$ & $1(11.1)$ & $2(22.2)$ & \multirow[t]{3}{*}{16.792} & \multirow[t]{3}{*}{0.010} \\
\hline Moderate & 23 & $6(26.1)$ & $8(34.8)$ & $8(34.8)$ & $1(4.3)$ & & \\
\hline Poor & 10 & 0 & $6(60.0)$ & 0 & $4(40.0)$ & & \\
\hline \multicolumn{8}{|l|}{ Infiltration depth } \\
\hline To the submucosa & 5 & 0 & $1(20.0)$ & $2(40.0)$ & $2(40.0)$ & \multirow[t]{3}{*}{14.981} & \multirow[t]{3}{*}{0.010} \\
\hline To the muscle & 22 & $1 \quad(4.5)$ & $10(45.5)$ & $7(31.8)$ & $4(18.2)$ & & \\
\hline To the outer layer & 15 & $5(33.3)$ & $9(60.0)$ & 30 & 1 (6.7) & & \\
\hline \multicolumn{8}{|l|}{ Tumor size (cm) } \\
\hline$<5$ & 29 & $4(13.8)$ & $15(51.7)$ & $5(17.2)$ & $5(17.2)$ & \multirow[t]{2}{*}{1.133} & \multirow[t]{2}{*}{0.769} \\
\hline$\geq 5$ & 13 & $2(15.4)$ & $5(38.5)$ & $4(30.8)$ & $2(15.4)$ & & \\
\hline \multicolumn{8}{|l|}{ Lymph node metastasis } \\
\hline Yes & 18 & $4(22.2)$ & $10(55.6)$ & $2(11.1)$ & $2(11.1)$ & \multirow[t]{2}{*}{3.954} & \multirow[t]{2}{*}{0.267} \\
\hline No & 24 & $2(8.3)$ & $10(41.7)$ & 7 (29.2) & $5(20.8)$ & & \\
\hline \multicolumn{8}{|l|}{ Distant metastasis } \\
\hline Yes & 23 & $6(26.1)$ & $12(52.2)$ & $2(8.7)$ & $3(13.0)$ & \multirow[t]{2}{*}{9.425} & \multirow[t]{2}{*}{0.024} \\
\hline No & 19 & 0 & $8(42.1)$ & $7(36.8)$ & $4(21.1)$ & & \\
\hline \multicolumn{8}{|l|}{ Clinical stage } \\
\hline $\mathrm{I}+\mathrm{II}$ & 26 & $1 \quad(3.8)$ & $2(46.2)$ & 7 (26.9) & $6(23.1)$ & \multirow[t]{2}{*}{7.882} & \multirow[t]{2}{*}{0.049} \\
\hline III+IV & 16 & $5(31.3)$ & $8(50.0)$ & $2(12.5)$ & $1(6.3)$ & & \\
\hline
\end{tabular}

Table V. Correlation between E-cadherin and CD44v6 expression in esophageal cancer.

\begin{tabular}{lrcccc}
\hline E-cadherin & No. & \multicolumn{5}{c}{ CD44v6 [n (\%)] } \\
\cline { 3 - 6 } & & - & + & ++ & +++ \\
\hline- & 22 & 0 & $8(36.4)$ & $9(40.9)$ & $5(22.7)$ \\
+ & 11 & $2(18.2)$ & $7(63.6)$ & 0 & $2(18.2)$ \\
++ & 6 & $2(33.3)$ & $4(66.7)$ & 0 & 0 \\
+++ & 3 & $2(66.7)$ & $1(33.3)$ & 0 & 0 \\
\hline $\mathrm{r}=-0.607, \mathrm{p}=0.001$. & & & \\
\hline
\end{tabular}

less frequently detected in EC than in adjacent normal tissue, consistent with the findings of Chung et al (18). Furthermore, absence of E-cadherin expression in EC was correlated with depth of invasion, lymph node metastasis, distant metastasis and clinical stage, indicating the relationship between loss of E-cadherin, and therefore loss of cell adhesion, and the invasion and metastasis of EC.

CD44s are another family of cell adhesion molecules that have been implicated in cancer. Owing to numerous splice variants, CD44 mediates different functions on different cells. In the physiological state, CD44 is mainly involved in inter-cell and cell-mesenchyma adhesion and mediation of lymphocyte homing and cell migration. One variant, CD44v6, changes the composition and function of adhesion molecules 
on the tumor cell surface of the tumor, which increases the invasive and metastatic abilities of tumor cells (19). Recent studies have confirmed that the overexpression of CD44v6 is closely correlated with incidence, development, invasion and metastasis of tumors $(20,21)$. In this study, we found that CD44v6 was more commonly expressed in EC tissue than in adjacent normal tissue, consistent with the findings of $\mathrm{Li}$ et al (22). Furthermore, CD44v6 expression was correlated with differentiation degree, distant metastasis and clinical stage. Thus, CD44v6 expression promotes the incidence, development and metastasis of EC and may therefore be useful as an indicator of prognosis in patients with tumors.

In addition to these findings, we identified a negative correlation between E-cadherin and CD44v6 expression in EC. E-cadherin and CD44v6 may therefore have negative synergistic effects in the pathology of EC: loss of E-cadherin and up-regulation of CD44v6 promotes the invasion and metastasis of tumor cells.

In conclusion, since the expression of E-cadherin and CD44v6 in EC is altered, detecting this expression may help determine the biological behavior, invasion and metastasis of these tumors. Additionally, these molecules may serve as reference indicators for prognosis evaluation of patients with $\mathrm{EC}$, aiding in the treatment and potentially improving the efficacy and survival rate of this disease.

\section{References}

1. Jemal A, Siegel R, Xu J and Ward E: Cancer statistics. CA Cancer J Clin 60: 277-300, 2010.

2. Rogers GJ, Hodgkin MN and Squires PE: E-cadherin and cell adhesion: a role in architecture and function in the pancreatic islet. Cell Physiol Biochem 20: 987-994, 2007.

3. Naor D, Wallach-Dayan SB, Zahalka MA and Sionov RV: Involvement of CD44, a molecule with a thousand faces, in cancer dissemination. Semin Cancer Biol 18: 260-267, 2008.

4. Liu YJ, Yan PS, Li J and Jia JF: Expression and significance of CD44s, CD44v6, and nm23 mRNA in human cancer. World J Gastroenterol 11: 6601-6606, 2005.

5. Giehl K and Menke A: Microenvironmental regulation of E-cadherin-mediated adherens junctions. Front Biosci 13: 3975-3985, 2008.

6. Yaldizl M, Hakverdi AU, Bayhan G and Akkuş Z: Expression of E-cadherin in squamous cell carcinomas of the cervix with correlations to clinicopathological features. Eur J Gynaecol Oncol 26: 95-98, 2005.
7. Harigopal M, Berger AJ, Camp RL, Rimm DL and Kluger HM: Automated quantitative analysis of E-cadherin expression in lymph node metastases is predictive of survival in invasive ductal breast cancer. Clin Cancer Res 11: 4083-4089, 2005.

8. Koksal IT, Ates M, Danisman A, Sezer C, Ciftcioglu A, Karpuzoglu G and Sevuk M: Reduced E-cadherin and alphacatenin expressions have no prognostic role in bladder carcinoma. Pathol Oncol Res 12: 13-19, 2006.

9. Jeanes A, Gottardi CJ and Yap AS: Cadherins and cancers: how does cadherin dysfunction promote tumor progression? Oncogene 27: 6920-6929, 2008.

10. Michaylira CZ, Wong GS, Miller CG, et al: Periostin, a cell adhesion molecule, facilitates invasion in the tumor microenvironment and annotates a novel tumor-invasive signature in esophageal cancer. Cancer Res 70: 5281-5292, 2010.

11. Moh MC and Shen S: The role of cell adhesion molecules in tumor suppression and cell migration: a new paradox. Cell Adh Migr 3: 334-336, 2009.

12. Swisher SG, Hofstetter W, Wu TT, et al: Proposed revision of the esophageal cancer staging system to accommodate pathologic response $(\mathrm{pP})$ following preoperative chemoradiation (CRT). Ann Surg 241: 817-820, 2005.

13. van Roy F and Berx G: The cell-cell adhesion molecule E-cadherin. Cell Mol Life Sci 65: 3756-88, 2008.

14. Wang L, Gao Y, Tu Q and Hong J: Expression of Ezrin and E-cadherin in nasopharyngeal carcinoma and its significance. Zhong Nan Da Xue Xue Bao Yi Xue Ban (in Chinese) 35: 969-975, 2010.

15. Dian D, Brüning A and Mylonas I: E-cadherin as a prognostic marker in human serous carcinomas of the ovary: an immunohistochemical analysis. Arch Gynecol Obstet 284: 437-443, 2011.

16. Jang TJ, Cha WH and Lee KS: Reciprocal correlation between the expression of cyclooxygenase-2 and E-cadherin in human bladder transitional cell carcinomas. Virchows Arch 457: 319-328, 2010.

17. Pryczynicz A, Guzińska-Ustymowicz K, Kemona A and Czyzewska J: Expression of the E-cadherin-catenin complex in patients with pancreatic ductal adenocarcinoma. Folia Histochem Cytobiol 48: 128-133, 2010

18. Chung Y, Lam AK, Luk JM, Law S, Chan KW, Lee PY and Wong J: Altered E-cadherin expression and p120 catenin localization in esophageal squamous cell carcinoma. Ann Surg Oncol 14: 3260-3267, 2007.

19. Goodison S, Urquidi V and Tarin D: CD44 cell adhesion molecules. Mol Pathol 52: 189-196, 1999.

20. Yu P, Zhou L, Ke W and Li K: Clinical significance of pAKT and CD44v6 overexpression with breast cancer. J Cancer Res Clin Oncol 136: 1283-1292, 2010.

21. Zhou DH, Ma ZM and Chen Y: Expression and clinical significance of CD44v6 and sCD44v6 in gastric carcinoma. Zhonghua Zhong Liu Za Zhi (in Chinese) 29: 833-837, 2007.

22. Li DM, Li SS, Zhang YH, Zhang HJ, Gao DL and Wang YX: Expression of human chorionic gonadotropin, CD44v6 and CD44v4/5 in esophageal squamous cell carcinoma. World J Gastroenterol 11: 7401-7404,2005. 